\title{
Study Subject Confidentiality Indicator
}

National Cancer Institute

\section{Source}

National Cancer Institute. Study Subject Confidentiality Indicator. NCI Thesaurus. Code C94154.

Specifies whether the study subject, or their legally acceptable representative, has not authorized the use and disclosure of their protected health information (i.e., the subject's data is private and confidential). 